\title{
Macrocell Corrosion and its Countermeasure for Reinforced Concrete after Patch Repair
}

\author{
Shinichi Miyazato ${ }^{1, *}$, Daishin Hanaoka ${ }^{1}$ \\ 'Department of Civil and Environmental Engineering, Kanazawa Institute of Technology, Ishikawa, 924-0838, Japan \\ *Corresponding author: E-mail: miyazato@neptune.kanazawa-it.ac.jp
}

DOI: $10.5185 /$ amlett.2020.061528

Reinforced concrete has been used in civil infrastructure development for several decades. However, steel bars used in some concrete structures are easily corroded by chlorides. In particular, when an existing concrete structure, after a patch repair, has a large quantity of unremoved chloride, local corrosions are generated in the steel bars. The purpose of this study is to analyze the macrocell corrosion mechanism in a reinforced concrete structure after a patch repair and to determine the influence of corrosion on structural performance. Additionally, a method to continue safely using reinforced concrete after a patch repair is proposed. The results of this study suggest that theoretically, the macrocell corrosion rate is high, based on an intersection point of an anodic and a cathodic polarization curves. It is also found that the macrocell corrosion increases when the chloride ion content exhibits a large difference. Additionally, it can be confirmed that increasing the extent of corrosion decreases the bending fracture load of the beam. Finally, a method is proposed to control macrocell corrosion.

\section{Introduction}

Reinforced concrete has been widely used in construction for several decades. However, the steel bars used in some concrete structures are often corroded by chloride ions after only a few years. Therefore, corrosion-inducing factors have to be removed from concrete structures during patch repairs. However, corrosion is locally generated in the steel bars if chloride ions remain in the structure after the completion of the repair process $[\mathbf{1 , 2}$. Because this is an unexpected effect, it is important for it to be addressed.

The structural performance of a reinforced concrete beam is designed for health situations without any deterioration and defect. However, the cross-sectional area of the reinforcing steel bar is reduced as a result of corrosion. Therefore, the structural performance of a corroded reinforced concrete beam must be determined. However, a loading test is extremely ineffective for reinforced concrete, with the local corrosion with a crack [3] being compared to the whole corrosion $[4,5]$. In particular there is no study about the local corrosion after the patch repair.

Considering this information, this study aims to analyze the macrocell corrosion mechanism, as well as its rate, in a reinforced concrete with a joint after a patch repair process, using not only theoretically anodic and cathodic polarization curves but also experimentally specimens with special divided steel bars. Also, this study determines the influence of the extent of corrosion on the structural performance of a reinforced concrete beam. Finally, a method to control the macrocell corrosion is proposed.
Corrosion mechanism in reinforced concrete

\section{Corrosion reaction}

A reinforcing steel bar in concrete is in a highly alkaline environment. Therefore, a passive film is formed around the steel, which protects it from corrosion. However, the corrosion of steel in concrete is accelerated if chloride ions are introduced. The corrosion of steel in concrete is called "wet corrosion" [6]. In an anode reaction (oxidation reaction), the iron present in steel ionizes, releasing two electrons. In contrast, in a cathode reaction (reduction reaction), these electrons are consumed when oxygen and water react. As a result, $\mathrm{Fe}(\mathrm{OH})_{2}$ is generated on the steel surface, in both anode and cathode reactions. Continuously, water is lost from $\mathrm{Fe}(\mathrm{OH})_{2}$, converting it to $\mathrm{Fe}_{2} \mathrm{O}_{3}$. As the result, rust is formed on the steel surface. Even if the rust is deep, because it is porous, the depression effect for corrosion is low. Therefore, corrosion always progresses after rust is formed. Moreover, an increasing pressure makes the concrete cover crack, because rust occupies a large volume (about 2-4 times the original volume of the steel). As a result, corrosion is further accelerated by a crack.

In accordance with the aforementioned discussion, during the corrosion reaction this study focuses on ions with various charges. This is the reason why corrosion is called an electrochemical reaction. The extent of rust corresponds to the corrosion current density; for example, the extent of corrosion is $1.2 \mathrm{~mm} / \mathrm{yr}$ when the corrosion current density is about $100 \mu \mathrm{A} / \mathrm{cm}^{2}$, as shown in Eq. (1).

$$
\begin{gathered}
\frac{100\left(\mu \mathrm{A} / \mathrm{cm}^{2}\right)}{96500(\mathrm{C})} \times \frac{55.85(\mathrm{~g} / \mathrm{mol})}{7.86\left(\mathrm{~g} / \mathrm{cm}^{3}\right) \times 2} \times 60(\mathrm{~s}) \times 60(\mathrm{~min}) \times 24(\mathrm{~h}) \\
=0.116(\mathrm{~cm} / \mathrm{yr})=1.2(\mathrm{~mm} / \mathrm{yr})
\end{gathered}
$$




\section{Advanced Materials Letters www. vbripress.com/aml}

\section{Corrosion cell formation pattern and rate}

The pattern of a corrosion cell is divided into "macrocell" and "microcell". Generally, the anode and cathode are clearly separated in the macrocell by a distance of over $10 \mathrm{~cm}$. However, the anode and cathode form at almost the same location in a microcell, in which case the separation is $1-2 \mathrm{~cm}$ or less.

(a)

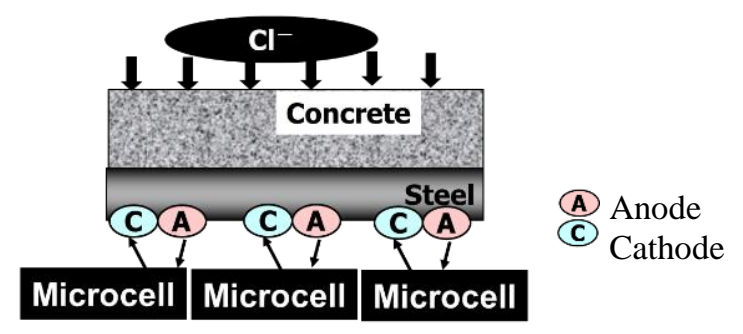

(b)

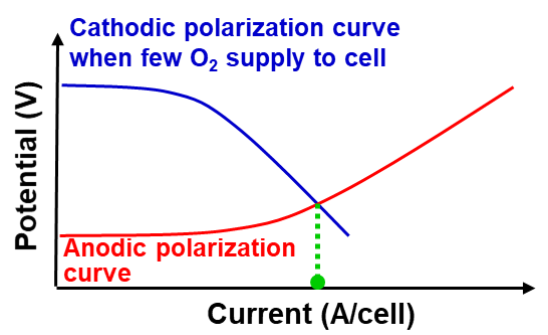

(c)

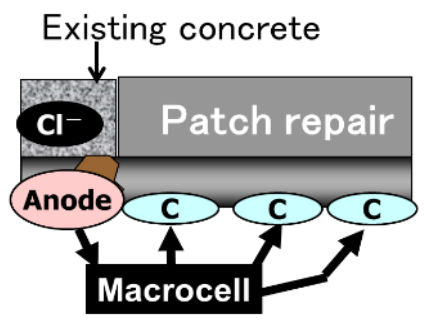

(C) Cathode

(d)

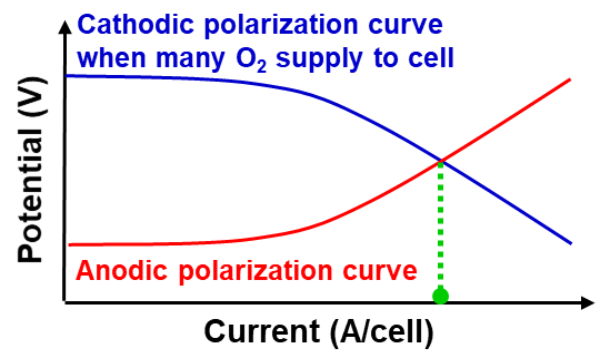

Fig. 1. (a) Image of whole corrosion (b) Polarization curves in microcell (c) Image of local corrosion after patch repair (d) Polarization curves in macrocell.

Here, the corrosion rates are compared between macrocell and microcell corrosions, using polarization curves. Fig. 1 shows an anodic and a cathodic polarization curves to not a unit area but a cell, under which a macrocell or microcell is formed. In spite of corrosion cell formation patterns, it is assumed that the passive film is destroyed at the anode part. Therefore, the shapes of anodic polarization curve are similar in both patterns. On the other hand, cathodic polarization curves are different for macrocell and microcell. In microcell, because the area of the cathode in one cell is narrow, only a small portion of oxygen is supplied to the cathode, as shown in Fig. 1(a). Thus, a cathodic polarization curve has a steep gradient, as shown in Fig. 1(b). As a result, the corrosion current produced at an intersection point of the anodic and cathodic polarization curves becomes small. On the other hand, an anode and a cathode are separated in a macrocell. In particular, only the part in which a passive film has been completely destroyed becomes an anode, and there is a cathode present in several other locations, as shown in Fig. 1(c). Therefore, the area of cathode in one cell is wide. That is, a lot of oxygen is supplied to the cathode and the cathodic polarization curve has an almost flat gradient, as shown in Fig. 1(d). As a result, the corrosion current as displayed in the intersection point of the anodic and cathodic polarization curves significantly increases. Consequently, it can be seen that the macrocell corrosion rate is higher than the microcell corrosion rate.

\section{Corrosion behavior after patch repair}

\section{Experiment procedure}

Fig. 2(a) shows the configuration of a concrete specimen and Fig. 2(b) and Fig. 2(c) show the configuration of a mortar specimen. The basic difference here is that in the repair side, the chloride ion content is lower, whereas it is higher in the existing side.

As for the concrete specimen, ordinary Portland cement, river sand, and crushed stone were used to imitate the existing side. The water cement ratio was $50 \%$ and the chloride ion concentrations were $0.5,2.0,7.0$ and 15.0 $\mathrm{kg} / \mathrm{m}^{3}$, respectively. Polymer cement mortar was used for another member that imitated the repair side. Additionally, as for the mortar specimen, ordinary Portland cement and river sand were used. The water cement ratios were $30 \%$, $50 \%, 100 \%$ and the chloride ion concentration was 15.0 $\mathrm{kg} / \mathrm{m}^{3}$ for the existing side. Mortar, whose water cement ratio was $50 \%$, without chloride ion was used for the repair side.

Moreover, a deformed steel bar of $10 \mathrm{~mm}$ diameter was used for the concrete specimen and a round steel bar of $9 \mathrm{~mm}$ diameter was used for the mortar specimen. The steel bar was composed of six elements for the purpose of measuring macrocell currents, as shown in Fig. 2(d) and Fig. 2(e) [7]. Two $70 \mathrm{~mm}$ long bars and four $40 \mathrm{~mm}$ long bars were used for the concrete specimen. Six $20 \mathrm{~mm}$ long bars were used for the mortar specimen. Lead wires were soldered at both ends of the segments before joining these egments with epoxy resin of high insulating capacity to form long bars.

Concrete or mortar was cast twice to form a joint. First, after the bar was placed at the center of the mold, the repair side material was placed and filled half of the mold (shown in the left side of Fig. 2 (a) and (b)). One day after casting, the existing side material was placed to completely fill up the mold (shown in the right side of Fig. 2(a) and (b)). This created a patch repair part with a joint. All specimens were subjected to initial curing in a wet environment of $20^{\circ} \mathrm{C}$ and $80 \%$ relative humidity $(\mathrm{RH})$ for 91 days after removal from the mold. 
(a)

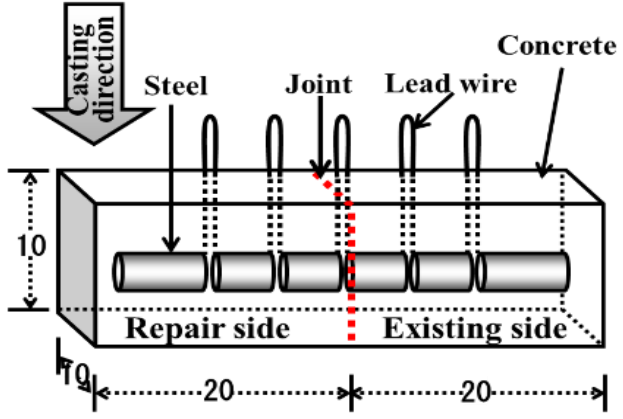

(b)

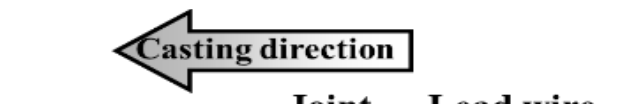

(c)

(d)
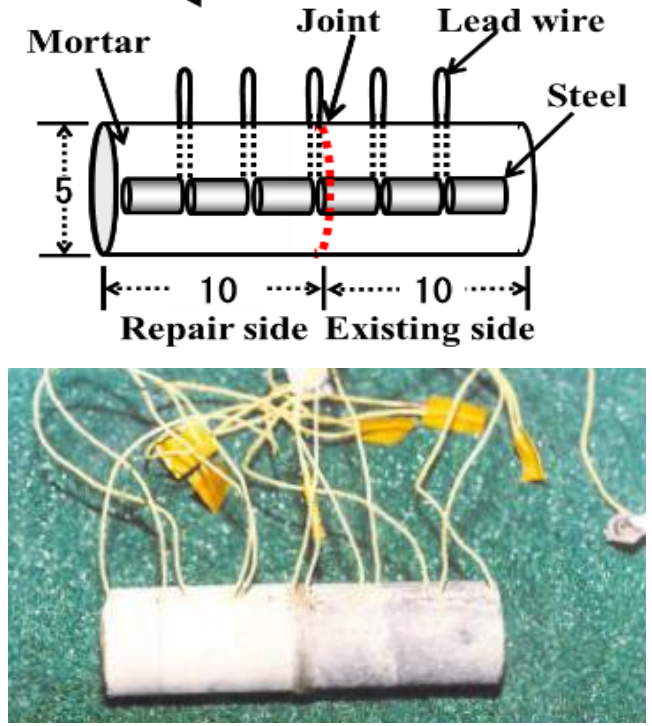

(e)

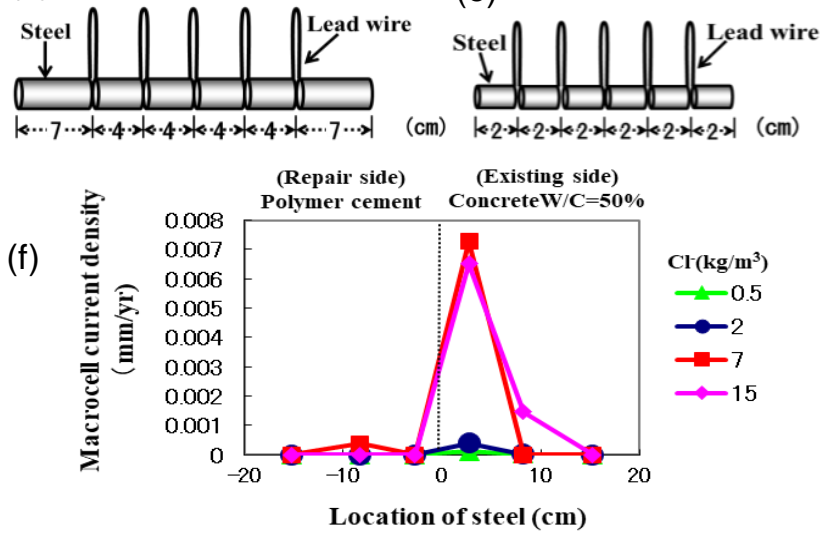

(g)

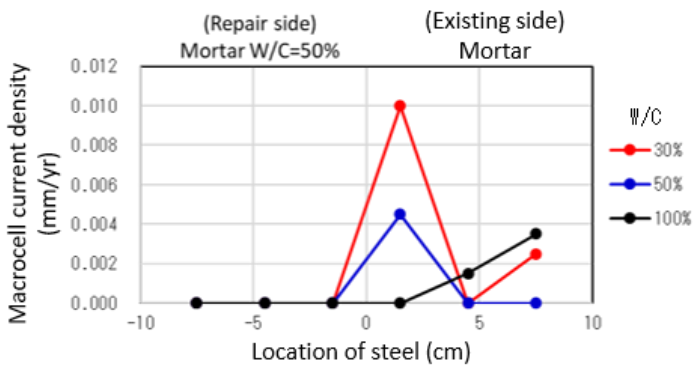

Fig. 2. (a) Concrete specimen configuration (b, c) Mortar specimen configuration (d) Special divided steel bar in concrete specimen (e) Special divided steel bar in mortar specimen (f) Macrocell current density distribution in concrete specimen (g) Macrocell current density distribution in mortar specimen.
The macrocell current was the total electric current flowing through all steel components taken as a unit. This current was measured using a no-resistance ammeter set between difference steel elements [8-10]. The macrocell current density was determined by Eq. (2). Therefore, the anodic current density is presented as positive, as follows:

$$
a_{i}=\frac{I_{i-1, i}-I_{i, i+1}}{S_{i}}
$$

where $a_{i}$ is the macrocell current density of the steel component $\mathrm{i}, \mathrm{I}_{\mathrm{i}, \mathrm{j}}$ is the macrocell current flowing from steel component $\mathrm{i}$ to component $\mathrm{j}$, and $\mathrm{S}_{\mathrm{i}}$ is the surface area of steel component i.

\section{Experiment results}

The influence of the chloride ion content in the existing side of the macrocell current densities is presented in Fig. 2(f). As shown in this figure, the macrocell currents of the steel bars embedded in the existing side, containing 7.0 and $15.0 \mathrm{~kg} / \mathrm{m}^{3}$ of chloride ions, are higher than those in the repair side without chloride ion. Therefore, it can be suggested that the steel bars in the existing side become the anode while those in the repair side become the cathode.

The influence of the water cement ratio in the existing side on the macrocell current densities is presented in Fig. 2(g). As shown in this figure, the steel bars in the existing side become the anode, regardless of the water cement ratio of the mortar in the existing side. Additionally, the macrocell current values are highest when the water cement ratio is $30 \%$. This reason seems to be that there is a big difference in material characteristics between the repair side and the existing side [10]. Therefore, it can be suggested that even if the water cement ratio is low, the macrocell forms between the existing side that is the anode and the repair side that is the cathode, and the corrosion rate is high.

\section{Structural performance of corroded beam after patch repair}

\section{Experiment procedure}

The reinforced concrete beam specimen shown in Fig. 3(a) was used. The water cement ratio was $57.5 \%$. The chloride ion content in the existing concrete was $2.0 \mathrm{~kg} / \mathrm{m}^{3}$ in No.1 and $15.0 \mathrm{~kg} / \mathrm{m}^{3}$ in Nos. $2-4$. After the initial curing, the specimen was exposed to iterative dry and wet environmental conditions $\left(40{ }^{\circ} \mathrm{C}, 50 \% \mathrm{RH}\right.$ for six days $+90 \% \mathrm{RH}$ for one day). After exposures lasting 10 or 20 months, the loading test, shown in Fig. 3(b), was performed. The compressive strength of concrete during the loading test was $18.3 \mathrm{~N} / \mathrm{mm}^{2}$. Next, after the reinforcing bar was removed, the longest and shortest diameters were measured with calipers, and an average was obtained. 
(a)

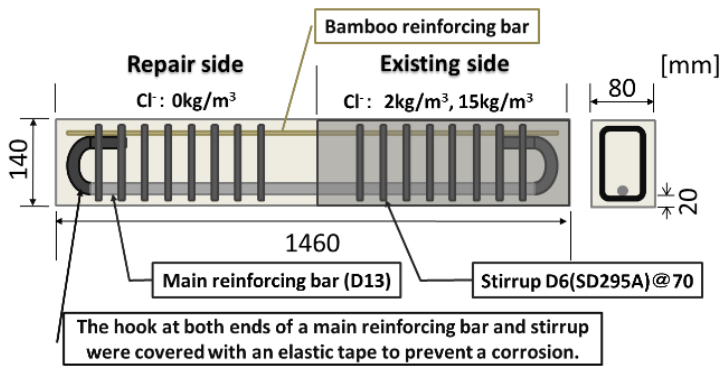

(b)

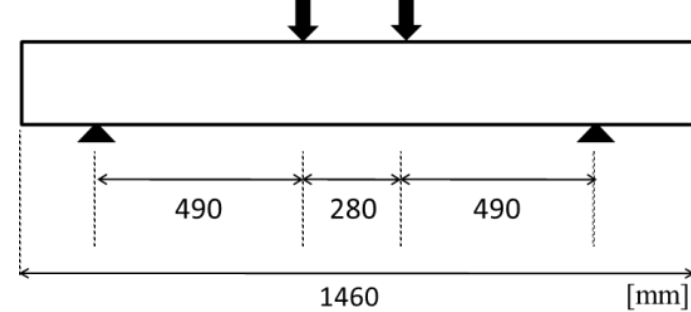

(c)

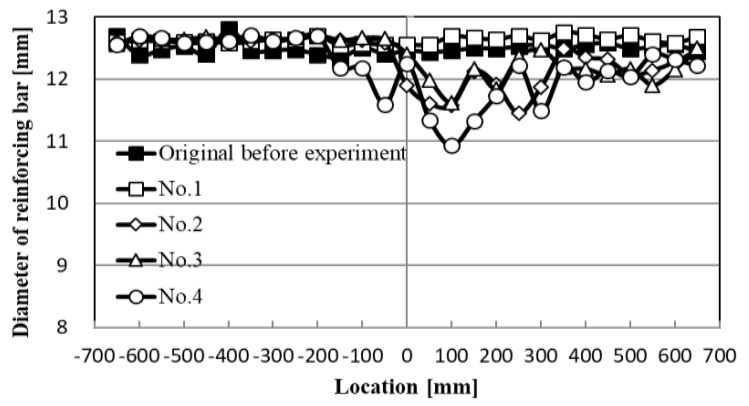

(d)

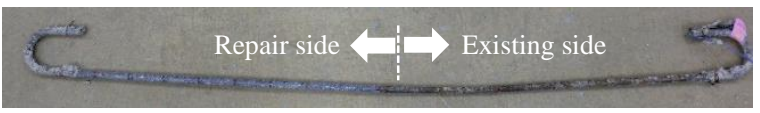

(e)

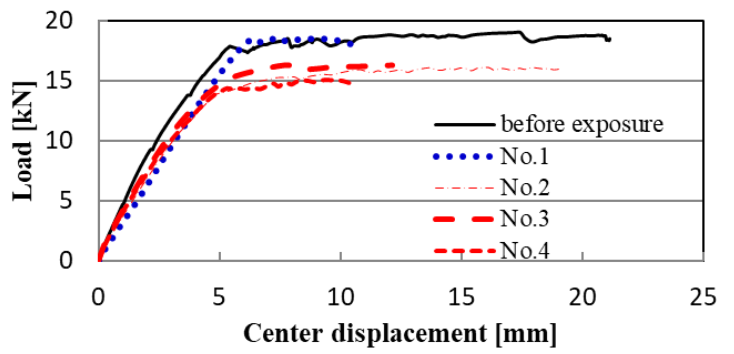

(f)

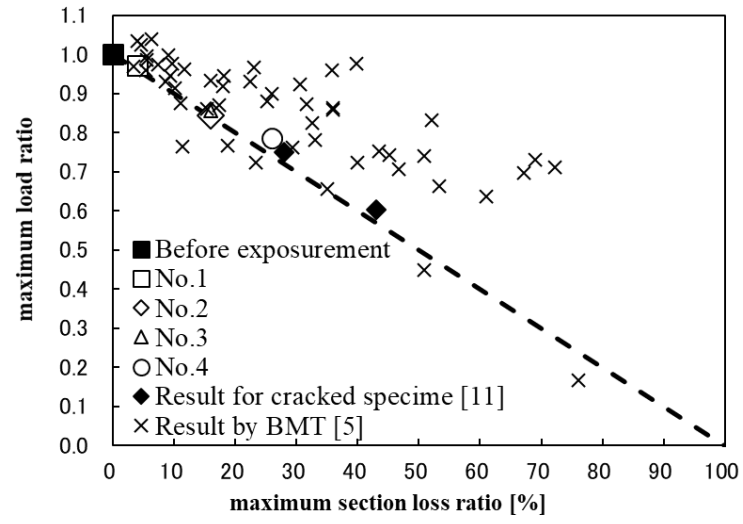

Fig. 3. (a) Specimen configuration (b) Situation regarding bending test (c) Distribution of reinforcing bar diameter (d) Situation of corroded rebar in No.2 (e) Load-center displacement curve (f) Relationship between maximum load ratio and maximum section loss ratio.

\section{Experiment result}

Fig. 3(c) shows the distribution of the diameter of the reinforcing bar and Fig. 3(d) shows an example of the situation of the corroded rebar. It can be stated that the diameter near the joint in the existing side decreases in Nos.2-4, as supported by these figures. Therefore, it was thought that the difference in the chloride concentration between the patch repair side and the existing concrete side caused the formation of the macrocell, and that local corrosion had occurred. Furthermore, the diameter of the reinforcing bar in No.1 is equal to the original value recorded before the experiment took place.

Fig. 3(e) shows the load-center displacement curve. According to this figure, it can be confirmed that the maximum value of the load decreases in Nos. 2-4. Moreover, the maximum value of the load of No.1 is equal to its recorded value before the exposure.

Fig. 3(f) shows the relationship between the maximum load ratio and the maximum section loss ratio. According to this figure, it can be clearly identified that decreasing the section of the reinforcing bar decreased the maximum value of the loading capacity. That is, it can be suggested that the structural performance is appreciable by the maximum section loss ratio of the reinforcing bar in the concrete beam that has caused the local corrosion by the macrocell following a patch repair.

\section{Countermeasure for corrosion after patch repair}

Idea

The following three ideas are proposed as a method of decreasing the macrocell corrosion formed between concretes with a different content of chloride ion based on an electrochemical theory. 1) The electrical resistance between the anode and the cathode increases to prevent forming the corrosion circuit. 2) The quantity of oxygen supplied for the cathode reaction decreases. 3) Concrete that contains chloride ion over the threshold is perfectly removed.

This study investigates the first idea. The water content of mortar decreases if a silane types penetrant is spread between the existing side and the repair side. As a result, the electrical resistance between the anode and the cathode becomes high, and the corrosion circuit is, hence, difficult to form.

This study verified the effect of the decrease of the corrosion rate after a patch repair using a silane type penetrant.

\section{Experiment procedure}

Fig. 4 (a) shows the configuration of the specimen. Ordinary Portland cement and land sand were used. The water cement ratio of mortar was $50 \%$ and the chloride ion content was $10.0 \mathrm{~kg} / \mathrm{m}^{3}$. Divided steel elements of No. I and II with $30 \mathrm{~mm}$ length were embedded in the mortar with a significant quantity chloride. The mortar that demolded after 24 hours was cured in wet air, at $20{ }^{\circ} \mathrm{C}$ and $90 \% \mathrm{RH}$ 


\section{Advanced Materials Letters www. vbripress.com/aml}

until the 28th day. Afterwards, the specimen was dried at $20{ }^{\circ} \mathrm{C}$ and $60 \% \mathrm{RH}$ for 7 days. Next, a joint surface was grounded with a sander, and the silane type penetrant, as shown in Table 1, was spread with a brush at $20{ }^{\circ} \mathrm{C}$ and 60\% RH, as shown in Fig. 4.

(a)

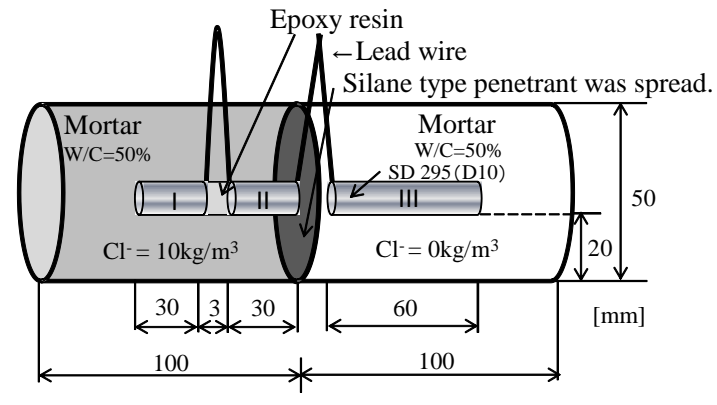

(b)

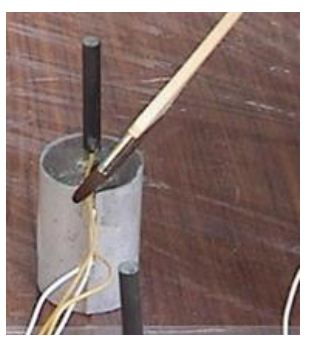

(c)

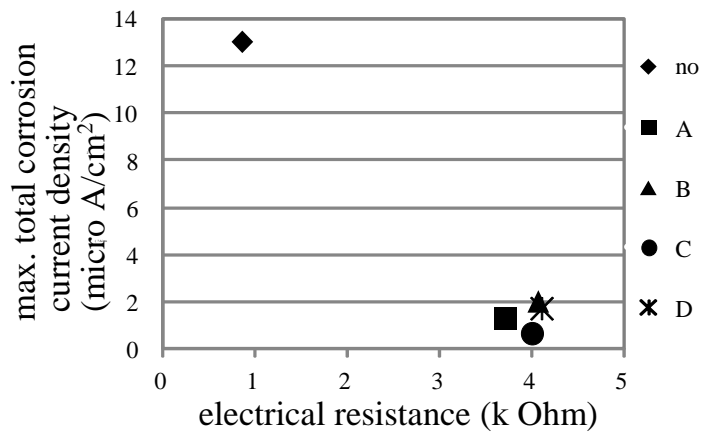

Fig. 4. (a) Specimen configuration (b) Spreading penetrant with brush (c) Relationship between electrical resistance and maximum value of total corrosion current density

Table 1. Penetrant used.

\begin{tabular}{|c|c|c|c|c|}
\hline \multirow[b]{2}{*}{ Case } & \multicolumn{3}{|c|}{ Characteristics } & \multirow[b]{2}{*}{$\begin{array}{c}\text { Amount of } \\
\text { spreading }\left(\mathrm{g} / \mathrm{m}^{2}\right)\end{array}$} \\
\hline & Principal component & State & \begin{tabular}{|l|} 
Density \\
$\left(\mathrm{g} / \mathrm{cm}^{3}\right)$
\end{tabular} & \\
\hline No & - & - & - & 0 \\
\hline $\mathrm{A}$ & Alkyl alkoxy silane & Liquid & 0.8 & 350 \\
\hline B & Silang siloxane & Gel & 0.9 & 200 \\
\hline $\mathrm{C}$ & Alkyl alkoxy silane & Gel & 0.8 & 200 \\
\hline $\mathrm{D}$ & Silang siloxane & Gel & 0.9 & 300 \\
\hline
\end{tabular}

(b). Here these four penetrants are considered as commercial items. After the specimen had cured for 7 days, continuously, in dry air, the mortar without chloride ion was jointed. Divided steel element of No. III with $60 \mathrm{~mm}$ length was embedded in this mortar. The specimen was wetted at $20{ }^{\circ} \mathrm{C}$ and $90 \% \mathrm{RH}$ for 7 days and exposed at $40{ }^{\circ} \mathrm{C}$ and $90 \% \mathrm{RH}$ for 21 days.
The total corrosion current density was evaluated at fourth week, after the joint formation. Thus, not only the macrocell current but also the microcell current were measured, and both current densities were added. The microcell current density was obtained from the measurement of the polarization resistance of the embedded steel bar. The polarization resistance was measured using an $\mathrm{AC}$ impedance method with a frequency response analyzer, undercutting the lead wire between each divided steel bar. The microcell current density for steel components are given as the following equation, based on literature survey $[\mathbf{1 2}, \mathbf{1 3}]$ :

$$
b_{i}=\frac{K}{R p_{i}}
$$

where, $b_{i}$ is the microcell current density of steel component $\mathrm{i}, \mathrm{Rp}_{\mathrm{i}}$ is the polarization resistance of steel component $\mathrm{i}$, and $\mathrm{K}$ is 0.0209 which is a constant.

An AC impedance device was set up between the divided steel elements of No.I and III after all lead wires had been cut, and the electrical resistance at a frequency of $10 \mathrm{kHz}$ was measured.

\section{Result}

Fig. 4(c) shows the relationship between the electrical resistance and the maximum value of the total corrosion current density. Here, the $\mathrm{Y}$-axis indicates the maximum value of the total corrosion current density measured at the divided steel element of No.I or II in the mortar with much chloride ions, as a representative. From this figure, it can be confirmed that the electrical resistance increases to 4.6 times, and the total corrosion current density decreases to $1 / 9$ in the sample on which the silane type penetrant was spread compared to the one without spreading. Thus, it can be seen that spreading the silane type penetrant between the anode and the cathode inhibits the formation of a corrosion circuit. Therefore, it can be verified that implementing the first idea, as previously stated, that "the electrical resistance between the anode and the cathode is increased, and the corrosion circuit is formed difficultly" decreases the macrocell corrosion after the patch repair. It can be thought that a bond strength between the materials and long-term durability at the interface should be discussed in the future.

\section{Conclusion}

In this study, the corrosion behavior and the structural performance were investigated after the patch repair. The conclusions are drawn as follows:

When existing concrete has a chloride ion concentration of $7 \mathrm{~kg} / \mathrm{m}^{3}$ or more, the difference in the chloride contents after the patch repair forms a macrocell. As a result, the corrosion rate becomes higher near the joint in the existing concrete, even though the water cement ratio of the existing concrete is low, and the section loss of the reinforcing bar is significant. On the other hand, when the chloride content in the existing concrete is $2 \mathrm{~kg} / \mathrm{m}^{3}$ or less, macrocell corrosion is not caused. 


\section{Advanced Materials Letters www. vbripress.com/aml}

Macrocell corrosion after the patch repair decreases the bending capacity of the beam. It is shown that the decreased ratio of the ultimate load can be calculated by the maximum amount of section loss of the reinforcing bar.

The macrocell corrosion after the patch repair decreased by spreading the silane type penetrant on the joint on the existing concrete. The reason for this seems to be that the electrical resistance between the anode and the cathode becomes high, and hence the formation of the macrocell becomes difficult.

Deterioration of road bridges and port installations is a social problem in Japan. The result of this study is expected to contribute positively to the safety and comfort of the lives of citizens.

\section{Acknowledgements}

Parts of this study were supported by Prof. Nobuaki Otsuki, Mr. Yoshihiko Tsukuda, Mr. Seiya Komatsu, NEXCO West Japan with Dr. Tetsuo Matsuda, and JSPS KAKENHI grant number 17H03289.

\section{Keywords}

Reinforced concrete, macrocell corrosion, patch repair, structural performance, inhibition.

Received: 22 July 2019

Revised: 02 September 2019 and

Accepted: 09 September 2019

\section{References}

1. Raupach, M.; Cement and Concrete Composites, 2006, 28, 679.

2. Eldho, C. A.; Nanayakkara O.; Xia, J.; Jones, S. W.; Key Engineering Materials, 2016, 711, 68.

3. Hanaoka, H.; Miyazato, S.; Yano, M.; The 10th Int. Conf. East Asia Pacific on Structural Engineering and Construction Proc. 245, 2006.

4. González, J.A.; Andrade, C.; Alonso, C.; Feliu, S.; Cement and Concrete Research, 1995, 25, 257.

5. Miyazato, S.; Shimomura, T.; Yamamoto, T.; Kato, Y.; 2nd Int. Conf. Structure Degradation Coastal Zones Proc. 549, 2010.

6. Beeby, A. W.; Concrete International, 1983, 2, 35.

7. Schiebl, P.; Raupach, M.; ACI Materials Journal, 1997, 94, 56.

8. Otsuki, N.; Miyazato, S.; Diola, N. B.; Suzuki, H.; ACI Materials Journal, 2000, 97, 454.

9. Nanayakkara, O.; Kato, Y.; Journal of Advanced Concrete Technology, 2009, 7, 31 .

10. Miyazato, S.; Otsuki, N.; Journal of Advanced Concrete Technology, 2010, 8,135 .

11. Miyazato, S.; Hoshino, A.; JSCE Ann. Conf. Proc. 143, Vol.5, 2009.

12. Tsuru, T.; Maeda, R.; Haruyama, S.; Corrosion Engineering, 1979, 28,638 .

13. Andrade, C.; Maribona, I. R.; Feliu, S.; Gonzalez, J. A.; Feliu, S. Jr; Corrosion Science, 1992, 33, 237. 